Original article

\title{
The effect of temperature and water stress on laboratory germination of Eucalyptus globulus Labill. seeds of different sizes
}

\author{
Marian López, Jaime M. Humara, Abelardo Casares and Juan Majada* \\ Dpto. Biología de Organismos y Sistemas, Unidad de Fisiología Vegetal, C/ Catedrático Rodrigo Uría s/n, and Instituto \\ Universitario de Biotecnología de Asturias-CNB (CSIC), Universidad de Oviedo, E-33071 Oviedo, Asturias, Spain
}

(Received 4 February 1999; accepted 16 August 1999)

\begin{abstract}
Germination rate and germination capacity of Eucalyptus globulus Labill. increased significantly with increasing temperature $\left(13^{\circ}\right.$ to $\left.33^{\circ} \mathrm{C}\right)$ for all seed sizes to an optimum at $28^{\circ} \mathrm{C}$, then decreased. Biggest seeds generally germinated best at all temperatures. Germination was also very sensitive to water potential ( 0 to $-0.75 \mathrm{MPa})$, with no germination occuring at potentials below $-0.25 \mathrm{MPa}$
\end{abstract}

Eucalyptus globulus / germination / polyethylene glycol / seed size / temperature / water potential

Résumé - Effet de la température et du stress hydrique sur la germination en laboratoire de graines d'Eucalyptus globulus Labill de différentes tailles. On a étudié l'influence sur la germination des graines d'Eucalyptus globulus Labill de températures constantes comprises entre $13^{\circ}$ et $33^{\circ} \mathrm{C}$ et de potentiels hydriques compris entre 0 et $-0,75 \mathrm{MPa}$. La germination était significativement influencée par la température et la taille des graines. La vitesse et le taux de germination augmentaient avec la température pour atteindre un optimum à $28^{\circ} \mathrm{C}$ et ensuite diminuaient. Quand la germination était effectuée en conditions de stress on observait une diminution du taux de germination entre $-0,01$ et $-0,75 \mathrm{MPa}$. Plus aucune graine ne germait à $-0,25 \mathrm{MPa}$ et au-delà.

Eucalyptus globulus / germination / dimension de la semence / température / potentiel hydrique

\section{INTRODUCTION}

Eucalypt pulp has excellent properties for paper making and is in high demand. The development of new pulping technologies and the potential to provide a low cost, uniform resource through silviculture, selection and breeding, suggest a continuing bright future for eucalypt plantations [26]. However, the cellulose pulp market in the European Union (EU) shows a supply shortage that is being compensated by imports from
South American countries or New Zealand. Productivity of plantations, particularly in Spain, through breeding and better management practices will result in a smaller area being required to produce the same amount of wood. This is especially important in the EU because regions where E. globulus, the most common eucalypt species in Europe, grows naturally are confined to southern warm and humid environments.

* Correspondence and reprints

Tel. 34-985104834; Fax.34-985104867; e-mail: jmajada@sci.cpd.uniovi.es 
Seed handling in the nursery is one factor that determines the time required for seed germination. Poor emergence of Eucalyptus spp. and delayed full emergence are serious limitations, not only in achieving efficient seed usage, but also in avoiding the additional production costs of pricking in. These problems are specially important when using seedlots from different provenances because seedling crops tend to be uneven. They are difficult to manage because larger plants from one seed source may shade smaller ones from another seed source, and also because watering regimens may have to be tailored to different sources. Consequently, the need for producing uniform seedling crops is increasing. Since germination synchrony partly determines seedling size, grade and overall quality, several practices including stratification, seed sizing, sowing by family and seed priming are used to enhance crop homogeneity and reduce cull percentages [22]. In spite of this, the response of eucalypt seeds in the nursery is normally quite low.

Eucalypt seed research has focussed mainly on germination responses of one particular species to only one or two environmental stimuli [1-4, 12, 14]. A more holistic approach to determine the effects of other environmental factors and their interactions in Eucalyptus occidentalis germination was described by Zohar and co-workers [28]. Likewise, Battaglia [2] demonstrated that sub- and supra-optimal temperatures and water stress interacted in their effect on cumulative germination and the germination rate of Eucalyptus delegatensis, revealing significant inter-provenance variations in germination traits. However, the main objective of these articles was to predict sowing times to optimise reforestation efforts, because regeneration following clear-felling of native overstorey trees is usually done by direct seeding.

The purpose of this report was to determine how temperature, water potential and seed size in E. globulus might be exploited to improve germination efficiency and seedling uniformity.

\section{MATERIALS AND METHODS}

E. globulus seeds of Flinders Island (Australia) provenance, obtained from a commercial supplier, were stored with silicagel in darkness at $4{ }^{\circ} \mathrm{C}$ before use. To study the effect of seed size on germination, seeds were sized using screens of different square mesh apertures: 1.2, 1.5, 1.7, 2 and $2.2 \mathrm{~mm}$, and divided into 5 different groups (sizes 1 to 5, respectively).

Germination tests were carried out in controlled environment chambers using cool-white fluorescent tubes $\left(16 \mathrm{~h}\right.$, photosynthetic photon flux of $90 \mu \mathrm{mol} \mathrm{m} \mathrm{m}^{-2} \mathrm{~s}^{-1}$ at the germination surface). Seeds for different experiments were placed in clear-plastic boxes $(600 \times 650 \times 60 \mathrm{~mm})$ on cellulose paper (Fanoia 1516/400) moistened with water through an absorbent wick except as indicated, then covered with $80 \mathrm{~mm}$ diameter Petri dishes to maintain the relative humidity close to $100 \%$. In the boxes the same volume of water or polyethylene glycol solutions was maintained.

To determine initial moisture content four replications of 100 seeds each of the two main sizes in a seedlot ( 3 and 4) and of an unsorted samples, were dried at $103^{\circ}-105^{\circ} \mathrm{C}$ for 17 hours [18]. Afterwards, seeds were removed and chilled for 5-10 minutes in a dessicator at room temperature, then weighed again to determine the loss of water suffered by the seeds. Seed imbibition rate was monitored at $10^{\circ}$ and $23^{\circ} \mathrm{C}$ by measuring the increases in seed weight at intervals after being placed on the moist cellulose medium.

Five replications of 100 seeds each from the five size classes were randomly placed in germination boxes, and tested over a range of sub- to supra-optimal constant temperatures of $13^{\circ}, 18^{\circ}, 24^{\circ}, 28^{\circ}$ and $33^{\circ} \mathrm{C}\left(\AA 2^{\circ} \mathrm{C}\right)$ that were based on data from Spanish nurseries that grow eucalypt seedlings.

For the purpose of this study, germination was considered as being complete when the radicle emerged from the seed. Germinated seeds were counted and removed every $24 \mathrm{~h}$ until germination stopped.

The rate of germination was estimated from the reciprocal of the time taken to reach $50 \%$ of the final cumulative germination, $T_{50}$, under the test conditions following the beginning of imbibition.

Germination was observed in a series of polyethylene glycol (PEG 8000, Sigma) solutions ranging from 0.01 to $0.75 \mathrm{MPa}$. PEG solutions were prepared according to Michel [20], and the 1 was verified using a vapour pressure osmometer (Wescor model 5500) calibrated against $\mathrm{NaCl}$ standards.

Four replications of 100 seeds each from seed size 3 were randomly placed in germination boxes. The cellulose paper was moistened with the PEG solutions except for a control that was moistened with distilled water. Based on results from the temperature experiments conducted previously, and because E. delegatensis seeds are less affected by moisture stress when germinated near the optimal temperature [2], the soil water potential experiments were conducted at $25^{\circ} \mathrm{C}\left( \pm 2{ }^{\circ} \mathrm{C}\right)$.

Differences in germination (capacity and rate) were subjected to analyses of variance [24]. Data transformations were used conducting an ad-hoc procedure for finding appropriate transformations to normalize the variables and achieve homogeneity of variances. 
Germination parameters were treated as dependent variables, temperature, seed size and time to germination as independent variables.

To examine the influence of temperature, size and water potential on germination, sigmoidal or Weibull models were used for determination of $T_{50}(r \geq 0.85)$ [9]. Germination rate and germination capacity were the dependent variables, whereas temperature, seed sizes and number of days until germination were the independent variables.

\section{RESULTS}

Germination of unsized E. globulus seeds was significantly affected by temperature (figure 1a). Visible signs of germination occured between 24 and 36 hours after sowing, being earlier at higher temperatures. Fastest and most complete germination occured at $28^{\circ} \mathrm{C}$ (figure $1 \mathrm{~b}$ ). Germination capacity declined at $33^{\circ} \mathrm{C}$, revealing $28^{\circ} \mathrm{C}$ as the optimum germination temperature for this unsorted seedlot.

Germination rate increased with temperature to an optimum of $28^{\circ} \mathrm{C}$ and then declined (figure $1 \mathrm{~b}$ ). The lower and upper temperature thresholds for germination of E. globulus were not encountered in this study, but were observed to be lower thatn $10^{\circ} \mathrm{C}$ and above $33^{\circ} \mathrm{C}$, respectively.

All size classes showed the same pattern of increasing germination rate with increasing temperature to a maximum at $28^{\circ} \mathrm{C}$, then a decrease (figure $1 \mathrm{c}$ ). Maximum germination capacities for sizes 1 and 2 occurred between 13 and $33^{\circ} \mathrm{C}$; for seed sizes 3 and 4 the maximum occurred between $18^{\circ}$ and $24^{\circ} \mathrm{C}$. While a significant interaction was found between temperature and seed size (table I), all seed sizes appeared to germinate well over a range of constant temperatures between $18^{\circ}$ and $28^{\circ} \mathrm{C}$. Although differences were small, seed sizes 4 and 5 appeared to be the least sensitive to temperature within this range. Maximal differences in germination capacity among seed sizes were found at $13^{\circ} \mathrm{C}$.

Germination rate was highest in all seed sizes at $28^{\circ} \mathrm{C}$ and above $28^{\circ} \mathrm{C}$, germination rate declined sharply for all seed sizes (figure 1d). A significant interaction between temperature and seed size on germination rate was observed (table Ib).

Seed sizes 3 and 4 imbibed at $23^{\circ} \mathrm{C}$ began germinating after approximately $36 \mathrm{~h}$. At this temperature, moisture levels increased quickly during the first $24 \mathrm{~h}$, then leveled off at around $63-75 \%$. This was followed by a period of relative slow water uptake, until RWC once again increased rapidly as radicle emergence commenced. Imbibition speed and moisture content increased as temperature increased: after 48 hours at $10^{\circ} \mathrm{C}$, moisture content was $60 \%$, but was $65 \%$ after 24 hours at $23^{\circ} \mathrm{C}$. Rate of imbibition and moisture level was higher in larger seeds: after 48 hours, size class 2 had a moisture content of $63 \%$, while size class 3 had reached $75 \%$.

Germination capacity and germination rate in size 3 seeds decreased with decreasing water potential (figures $1 e$ and $1 f$ ). Although osmotic potentials of $-0.01 \mathrm{MPa}$ had little effect on germination capacity, potentials greater than -0.05 greately reduced germination and no seeds germinated under water potentials of $-0.25 \mathrm{MPa}$ or lower (figure 1e), despite the high relative humidities maintained during the tests. The response of germination rate to water potential was similar (figure lf).

Table I. Analysis of variance table for temperature and seed size effects.

\begin{tabular}{|c|c|c|c|c|c|}
\hline Source & d.f. & Sum of squares & Mean square & $F$ value & $P$ \\
\hline \multicolumn{6}{|c|}{ (a) Germination capacity } \\
\hline Temperature & 4 & 1.296 & 0.324 & 34.810 & 0.001 \\
\hline Size & 4 & 1.671 & 0.418 & 44.906 & 0.001 \\
\hline Interaction & 16 & 0.485 & 0.03033 & 3.26 & 0.001 \\
\hline \multicolumn{6}{|c|}{ (b) Germination rate $\left(1 / T_{50}\right)$} \\
\hline Temperature & 4 & 1.214 & 0.303 & 273.39 & 0.001 \\
\hline Size & 4 & 0.290 & 0.072 & 65.40 & 0.001 \\
\hline Interaction & 16 & 0.088 & 0.0055 & 4.99 & 0.001 \\
\hline
\end{tabular}



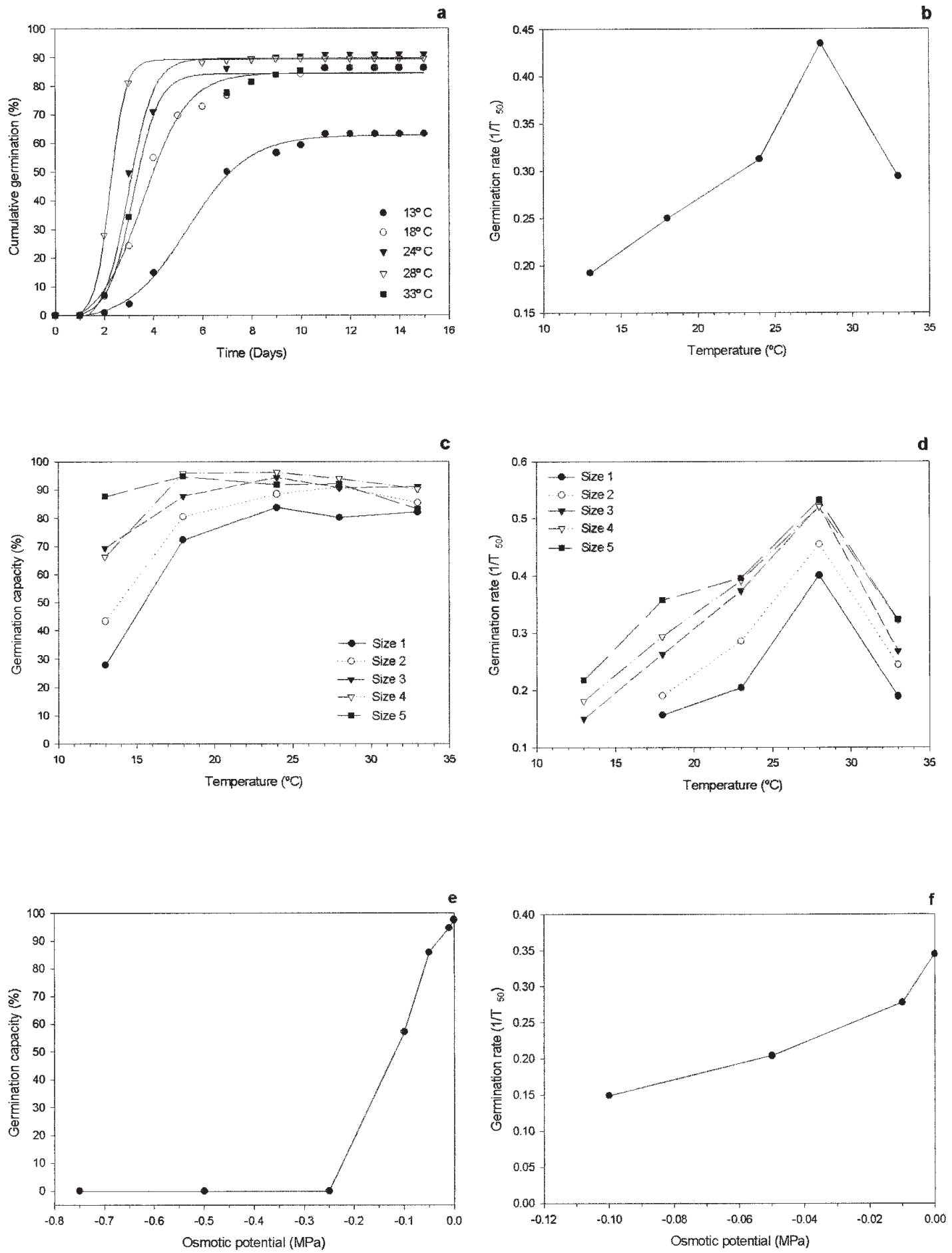

Figure 1. The effect of temperature, water stress and seed size on germination of E. globulus. a) Effect of temperature on germination capacity of an unsorted lot. b) Effect of temperature on germination rate of an unsorted lot. c) Effect of temperature and seed size on germination capacity. d) Effect of temperature and seed size on germination rate. e) Effect of water potential on germination capacity of seed size class 3 at $25^{\circ} \mathrm{C}$. f) Effect of water potential on germination rate of seed size class 3 at $25^{\circ} \mathrm{C}$. 


\section{DISCUSSION}

The results demonstrated that the supra-optimal temperature became lower as E. globulus seed size increased. An optimum temperature for germination rate was determined $\left(28^{\circ} \mathrm{C}\right)$, which is supported by the findings of Battaglia [2]. The difficulty encountered by other authors to clearly recognize an optimum temperature might partly result from the graphical representation of the data used by different authors, whether they prefer to use the germination energy index (GEI) or the reciprocal of time to reach $50 \%$ of germination $\left(T_{50}\right)$. When GEI was calculated in our work, only a slight decline in rate above the optimum was observed. The GEI effectively integrates the area under the germination curve and takes it as a proportion of the area as defined by the product of the time to maximum germination and the germination capacity. According to Battaglia [2], increasing the ratio of these areas, long-tailed or positively skewed distributions reduce the sensitivity of the GEI to changes in germination rate. By contrast, the $T_{50}$ measure, which takes into account the average slope of what is normally the steepest part of the cumulative germination curve, is reasonably robust in this regard, facilitating the identification of an optimum temperature for the seedlot studied which, as previously detailed, was $28^{\circ} \mathrm{C}$ for all sizes of E. globulus tested in this study.

Earlier work on E. globulus recommended an optimal temperature of $25^{\circ} \mathrm{C}$ [6], whereas Eucalyptus species growing in South Africa did best at $17-22^{\circ} \mathrm{C}$ [11]. An optimum of $15^{\circ}$ and $20^{\circ} \mathrm{C}$ has been reported for E. Delegatensis, and while short periods of higher temperature did not seriously affect germination [2], other researchers have shown adverse effects of high temperature on germination capacity of this species [16].

The presence of an optimum temperature above and below which the rate of germination declines has been noted in several reviews $[5,7]$. The decline in rate of germination with decreasing ambient temperature partly results from the decline in the imbibition rate observed with a reduction in temperature. Moreover, according to Bewley and Black [5], the rate of water penetration into seeds is critical to the success of germination. A higher speed in imbibition was recorded for higher temperatures and larger sizes, what led to a faster protrusion of the radicle. A decrease in temperature is related to an increase in the time necessary to reach RWCs similar to those for seeds imbibed at higher temperatures. It can be concluded that under the experimental conditions tested here, E. globulus seeds begin their radicle emergence when their RWC is close to $70 \pm 5 \%$.

Reports on the effect of seed size on germination in eucalypts are contradictory $[23,27]$. In this study seed- size effects were significant for several temperatures, demonstrating that sorting is essential to achieve germination uniformity in E. globulus, and that seed size has operational importance. When seedlot size varies widely, as in E. globulus, larger within- lot variability in germination parameters can be expected. The results reported here are supported by studies on other species [21], although the use of only two or tree size fractions may have masked some of the variation as was demonstrated for Sitka spruce [10].

Water deficits below $-0.01 \mathrm{MPa}$ were required to affect germination of E. globulus seeds, results that agree substantially for a range of other eucalypt species some of which showed decreases in germination at deficits of only $-0.003 \mathrm{MPa}[1,14,15]$. Whereas Battaglia [2] found $E$. delegatensis was unaffected by matric potentials as high as $-0.1 \mathrm{MPa}$, he pointed out that most experiments on water stress are done directly on a sintered plate. This provides a medium on which seed contact is poor and, consequently, seeds could be highly susceptible to any decline in moisture level. In the study reported here, seeds were placed directly on and in good contact with the germination medium and were kept under $98 \%$ relative humidity.

Acknowledgments: For this work, M. López, and J.M. Humara were partly supported by the contract FC97-PA-REC97-02 funded by the "II Plan Regional de Investigación" of the Principado de Asturias (Spain), and by Celulosas de Asturias S.A. (CEASA, Navia, Asturias, Spain). We sincerely thank Consuelo Gómez and Roberto Astorga for their assistance in setting up some of the trials, and their helpful comments on the development of the research.

\section{REFERENCES}

[1] Bachelard E.P., Effects of soil moisture stress on the growth of seedlings of three eucalypt species. I. Seed germination, Aust. For. Res. 15 (1985) 103-114.

[2] Battaglia M., Seed germination physiology of Eucalyptus delegatensis R.T. Baker in Tasmania, Aust. J. Bot. 41 (1993) 119-136.

[3] Battaglia M., Modelling seed germination and seedling survival of Eucalyptus delegatensis R.T. Baker to facilitate optimal reafforestation, Ph.D. Thesis, University of Tasmania, 1993.

[4] Battaglia M., Seed germination model for Eucalyptus delegatensis provenances germinating under conditions of variable temperature and water potential, Aust. J. Plant Physiol. 24 (1997) 69-79. 
[5] Bewley J.D., Black M., Seeds. Physiology of development and germination, Plenum Press, New York, 1994.

[6] Boland D.J., Frooker M.I.H., Turnball, J.W., Eucalyptus seed. CSIRO Australia, Melbourne, 1980, pp. 191.

[7] Bradford J.K., Water relations in seed germination, in: Kigel J., Galili G. (Eds.), Seed development and germination, Marcel Dekker, Inc. New York, 1995, pp. 351-390.

[8] Bradford J.K., Dahal P., Ni B.-R., Quantitative models describing germination responses to temperature, water potential, and growth regulators, in: Côme D., Corbineau F. (Eds.), Fourth international workshop on seeds: basic and applied aspects of seed biology, Vol. 1, Association pour la Formation Professionnelle de l'Interprofession Semences, Paris, 1993, pp. 239-248.

[9] Brown R.F., Mayer D.G., Representative cumulative germination. 2. The use of the Weibull function and other empirically derived curves, Ann. Bot. 61 (1988) 127-138.

[10] Chaisurisri K., Edwards D.G.W., El-Kassaby Y.A., Genetic control of seed size and germination in Sitka spruce, Silvae Genet. 41 (1992) 348-355.

[11] Donald D.G., Jacobs C.B., The effect of temperature on the germination capacity and dormancy percent of seed of cold tolerant Eucalyptus species, Seed Sci. Technol. 21 (1993) 255-268.

[12] Edgar J.G., Effects of moisture stress on germination of Eucalyptus camaldulensis Dehnh. and E. regnans F. Muell., Aust. For. Res. 7 (1977) 241-245.

[13] Fenner M., Environmental influences of seed size and composition, Hort. Rev. 13 (1992) 183-213.

[14] Gibson A., Bachelard E.P., Germination of Eucalyptus sieberi, L. Johnson seeds. I. Response to substrate and atmospheric moisture, Tree Physiol. 1 (1986) 57-65.

[15] Gibson A., Bachelard E.P., Germination of Eucalyptus sieberi, L. Johnson seeds. II. Internal water relations, Tree Physiol. 1 (1986) 66-77.

[16] Grose R.J., The silviculture of Eucalyptus delegatensis, Part 1, Germination and seed dormancy,
University of Melbourne, Bulletin $\mathrm{N}^{\mathrm{o}}$ 2, Melbourne, 1963.

[17] Gutterman Y., Maternal effects on seeds during development, in: Fenner M. (Ed.), Seeds. The ecology of regeneration in plant communities, Wallingford, CAB International, 1992, pp. 27-59.

[18] International Seed Testing Association (ISTA). International rules for seed testing, Seed Sci. Technol. 4 (1976) 3-177.

[19] McWilliam J.R., Phillips P.J., Effect of osmotic and matric potentials on the availability of water for seed germination, Aust. J. Biol. Sci. 24 (1971) 423-431.

[20] Michel B.E., Evaluation of the water potentials of solutions of polyethylene glycol 8000 both in the absence and presence of other solutes, Plant Physiol. 72 (1983) 66-70.

[21] Milberg P., Andersson L., Elfverson C., Regnér S., Germination characteristics of seeds differing in mass, Seed Sci. Res. 6 (1996) 191-197.

[22] Mohammed G.R., The status and future of stock quality testing, New For. 13 (1997) 491-514.

[23] Ni B.R., Bradford, K.J., Quantitative models characterizing seed germination responses to abscisic acid and osmoticum, Plant Physiol. 98 (1992) 10571068.

[24] SAS Institute Inc., 1988, SAS ${ }^{\circledR}$ Technical Report P-179, Additional SAS/STAT procedures, Release 6.03. SAS Institute, Cary, NC.

[25] Stamp N.E., Production and effect of seed size in a grassland annual (Erodium brachycarpum Geranizaceae), Am. J. Bot. 77 (1990) 874-882.

[26] Turnbull J.W., Future use of Eucalyptus: opportunities and problems, in: Proceedings of the IUFRO symposium "Intensive Forestry: The role of Eucalypts", 1991, pp. 2-27.

[27] Zammint C., Zedler P.H., Seed yield, seed size and germination behaviour in the annual Pogoyne abramsii, Oecologia 84 (1990) 28-48.

[28] Zohar Y., Waisel Y., Karschon, R., Effects of light, temperature and osmotic stress on seed germination of Eucalyptus occidentalis Endl., Aust. J. Bot. 23 (1975) 391-397. 